\title{
Alterations in human breast cancer adhesion-motility in response to changes in cell surface glycoproteins displaying $\alpha$-L-fucose moieties
}

\author{
KUN YUAN ${ }^{1}$, DENNIS KUCIK ${ }^{1,5}$, RAJ K. SINGH ${ }^{1,6}$, CATHERINE M. LISTINSKY ${ }^{1,7}$, \\ JAY J. LISTINSKY ${ }^{2,8}$ and GENE P. SIEGAL ${ }^{1,3-5}$ \\ Departments of ${ }^{1}$ Pathology, ${ }^{2}$ Diagnostic Radiology, ${ }^{3}$ Cell Biology, and ${ }^{4}$ Surgery, University of Alabama at Birmingham, \\ Birmingham, AL 35233; ${ }^{5}$ Birmingham VA Medical Center, Birmingham, AL 35233, USA
}

Received September 21, 2007; Accepted November 19, 2007

\begin{abstract}
Glycosylation of proteins plays multiple roles in cell-cell and cell-matrix interactions. Fucose is a monosaccharide associated with glycosylation events and is known to be over-expressed in many malignant tumors. By using $\alpha$-L-fucosidase ( $\alpha$-L-fase), a glycosidase that specifically removes $\alpha$-L-fucose ( $\alpha$-L-f), we have examined the potential effects of defucosylation on tumor functions, focusing on tumor progression in the context of the interaction of tumor cells with the extracellular microenvironment. In this submission, we report that $\alpha$-L-fase treatment decreases, in static assays, tumor cell adhesion to a wide variety of ECM components including fibronectin, laminin, collagen I, hyaluronic acid and the complex human biomatrix, HuBiogel ${ }^{\circledR}$. By immunofluorescence, co-localization of $\beta_{1}$ integrin and $\alpha-\mathrm{L}-\mathrm{f}$ was found to decrease accordingly. Sialyl Lewis $\mathrm{X}$, an $\alpha$-L-f-containing tetrasaccharide, which modulates the rolling of leukocytes and tumor cells on
\end{abstract}

Correspondence to: Professor Gene P. Siegal, Division of Anatomic Pathology, Department of Pathology, KB 506, 619 19th St. South, University of Alabama at Birmingham, Birmingham, AL 35233, USA

E-mail: gsiegal@path.uab.edu

Present address: ${ }^{6}$ Vivo Biosciences, Inc., Birmingham, AL; ${ }^{7}$ Department of Pathology, ${ }^{8}$ Department of Radiology, CaseWestern, Reserve University School of Medicine, Cleveland, $\mathrm{OH}$, USA

Abbreviations: Ulex, Ulex europeans agglutinin I; sLe X, sialyl Lewis X; sLe A, sialyl Lewis A; Le X, Lewis X; FucT, fucosyltransferase; mAb, monoclonal antibody; ECM extracellular matrix; $\alpha$-L-f, $\alpha$-L-fucose; $\alpha$-L-fase, $\alpha$-L-fucosidase

Key words: breast cancer, fucose, fucosidase, glycosylation, selectin endothelium, was found to be diminished on human breast cancer cells after $\alpha$-L-fase treatment. Using a dynamic flow chamber system, we were able to determine that defucosylation impaired the rolling of mammary cancer cells on human umbilical vein endothelial cells while significantly increasing their flow speed. Further, the rolling capability of these defucosylated tumor cells was also impaired on purified E and P-selectin matrices. Based on these data, we hypothesize that decreased fucosylation impairs the interaction between tumor cells and their external milieu, which in turn, affects key cell functions modulating tumor progression. Building on our previous studies which demonstrated $\alpha$-L-fase decreased tumor cell invasion while significantly reducing MMP-9 activity, when added to the fact that decreased adhesion on HUVEC occurs in the presence of $\alpha$-L-fase also leads us to propose that defucosylation may modulate metastasis, and thus provides a promising additional glycobiotic target for novel therapies.

\section{Introduction}

Glycosylation drives the specific arrangement of oligosaccharides linked to glycoproteins or glycolipids, thereby participating in various important physiologic and pathologic events. Changes in cell surface glycosylation are common features of malignant transformation and aberrant glycosylation is functionally involved in key steps of neoplastic progression including tumor invasion and evasion of host immunosurveillance $(1,2)$. Certain glycosylation patterns expressed by tumor cells are recognized to modulate the adhesion of tumor cell to extracellular matrices and to the endothelium. Selected molecules in the Lewis antigen family such as Lewis X (Le X), sialyl Lewis X (sLe X) and sialyl Lewis A (sLe A) either directly constitute adhesion ligands (3) or indirectly influence the function of molecules that comprise the adhesome (4-6).

$\alpha$-L-fucose $\left(\mathrm{C}_{6} \mathrm{H}_{12} \mathrm{O}_{6}\right)$, a monosaccharide component of glycosylation, participates in many cell-cell and cell-matrix interactions. $\alpha$-L-f expression has been found to be elevated in various types of solid tumors and the level of the elevated fucose often correlates directly with tumor progression. 
Equally importantly, $\alpha$-L-f has also been found to be preferentially expressed in metastatic foci as compared with primary tumor sites (7). In these types of investigations, the functional role of $\alpha-\mathrm{L}-\mathrm{f}$ was principally manifest through fucose-containing glycans, Lewis antigens (specifically, sialyl Lewis X [NeuAc $\alpha 2,3$ Galß1,4(Fuc $\alpha 1,3)$ GlcNAc] and sialyl Lewis A [NeuAc $\alpha 2,3 \mathrm{Gal} \beta 1,3$ (Fuc $\alpha 1,4)$ GlcNAc]). Sialyl Lewis antigens have been found to be elevated in tumor tissues, modulate tumor cells interactions with endothelium and facilitate hematogenous metastasis $(3,8,9)$.

Breast cancer remains among the most common malignant tumors and ranks second in mortality among American women. Irrespective of modern advances, the prognosis continues to largely depend on the extent of tumor invasion and distant metastasis at the time of discovery (10). Hematogenous metastasis, in turn, is a complex multistage process involving tumor proliferation, migration, invasion, neoangiogenesis, and subsequent arrest of viable neoplastic/ transformed cells on distant endothelium resulting in clonal expansion at metastatic sites. Elevated fucosylation has been found in mammary malignancies and their prognosis is closely correlated with these phenotypic markers of neoplastic progression (11). Furthermore, the positive expression of sLe $\mathrm{X}$ in primary breast cancer cells has been shown to be correlated with both lymph node involvement and reduced disease-free survival rates $(12,13)$.

As $\alpha$-L-f-containing molecules are closely correlated with neoplastic progression, an argument has been put forth that it is rationale to explore the modification of the $\alpha$-L-f expression on tumor cell surfaces as a therapeutic target (7). We hypothesized that decreasing $\alpha$-L-f expression would alter biological behaviors of breast cancer cells, especially the interactions between tumor cells, extracellular matrix (ECM) and endothelial cells and would, thus, provide novel pre-clinical information.

\section{Materials and methods}

Cell lines. MDA-MB-231, a highly invasive human breast cancer cell line obtained from the American Type Culture Collection (Manassas, VA) was cultured in Leibovitz's (L-15) medium supplemented with $10 \%$ fetal bovine serum (both from the Media Preparation Shared Facility, University of Alabama at Birmingham, AL). These MDA-MB-231 cells were maintained at $37^{\circ} \mathrm{C}$ in a humidified atmosphere without supplemental $\mathrm{CO}_{2}$ as recommended by the supplier. CRL1730 HUVEC (human umbilical vein endothelial cells) were similarly purchased from the ATCC and cultured in Ham's F12K complete growth medium (ATCC 30-2004), supplemented with $10 \%$ fetal bovine serum and $0.03 \mathrm{mg} / \mathrm{ml}$ of endothelial cell growth supplement (Sigma, St. Louis, MO). HUVEC cells were cultured on $3.5-\mathrm{cm}$ plastic culture dishes $\left(\mathrm{Costar}^{\circledR}\right.$, Corning, $\left.\mathrm{NY}\right)$, at $37^{\circ} \mathrm{C}$, in a humidified atmosphere with $5 \% \mathrm{CO}_{2}$ supplementation.

Antibodies, lectins and related reagents. Rabbit anti-human CD44 polyclonal antibody; HCAM-1 (Santa Cruz Biotechnology, Santa Cruz, CA) and mouse anti-human sialyl Lewis $\mathrm{X}$ mAb, Km93 (Calbiochem, La Jolla, CA) were used in selective experiments. Biotin and FITC labeled Ulex europeans agglutinin I (Ulex) were purchased from EY Labs (San Mateo, CA) and Caltag (Burlingame, CA). Collagen I, Gelatin, Heparin, Hyaluronic Acid and $\alpha$-L fucosidase (from bovine epididymis) were all purchased from Sigma Chemical Co. Calcein, CellTrace ${ }^{\mathrm{TM}}$ Calcein Red Orange, Alexa 647 goat anti-mouse IgG, Alexa 647 anti-mouse IgM, and streptavidin conjugated Alexa Fluor 488 were all purchased from Molecular Probes (Eugene, OR). All other chemicals were obtained from Sigma Chemical Co., if not individually specified.

HuBiogel ${ }^{\circledR}$ human extracellular matrix. HuBiogel was kindly provided by Vivo Biosciences (Birmingham, AL). HuBiogel is a biologically active, complex extracellular matrix gel derived from normal, full-term human placental amniotic membranes. The major components of HuBiogel are types I and IV collagen, laminin, entactin, tenascin, and heparan sulfate proteoglycan. Under defined conditions of production, EGF, TGF- $\alpha$, TGF- $\beta_{1-3}$, FGF $_{1 \& 2}$ and PDGF along with MMP2 and 9 are non-detectable (14).

$\alpha$-L-fucosidase treatment. $\alpha$-L-fucosidase ( $\alpha$-L-fase), purchased from Sigma Chemical Co., was diluted in sterile PBS. $1.69 \mathrm{mU} / \mathrm{ml}\left(8.8 \mathrm{mU} / 10^{6}\right.$ cells $)$ was found to maximally reduce $\alpha$-L-f expression on MDA-MB-231 human breast cancer cells without significantly affecting cell viability. Briefly, cells were cultured to $70-80 \%$ confluence, trypsinized $(0.25 \%)$, washed with PBS twice and cell numbers determined manually. $\alpha$-L-fase was mixed with tumor cells to the desired concentration and then incubated, at $37^{\circ} \mathrm{C}$ for 30 min. Finally, cells were washed with PBS and centrifuged to remove any residual $\alpha$-L-fase.

Flow cytometry. Cells were treated with $\alpha$-L-fase as described above. An equal number of cells were treated with PBS as control. Both groups of cells were incubated with Ulex europaeus I lectin labeled with FITC. In parallel, negative (unlabeled) control samples were sham treated with the appropriate isotope control and run in parallel with an untreated autofluorescence control. The detection of sLe X by flow cytometry has been reported previously (15). Briefly, detached MDA-MB-231 cells were washed and re-suspended in PBS containing $1 \% \mathrm{BSA}$, then incubated with the $\mathrm{Km} 93$ $\mathrm{mAb}$ against sLe $\mathrm{X}$ (1:50 dilution), for $30 \mathrm{~min}$ at $4^{\circ} \mathrm{C}$. After two washes, cells were incubated for $45 \mathrm{~min}$ at $4^{\circ} \mathrm{C}$, with a 1:200 dilution of FITC-conjugated goat antibodies against mouse IgM. Cells were again washed with PBS and fixed in $1 \%$ paraformaldehyde prior to flow cytometric analysis. Flow cytometry was performed on a B-D FACS caliber instrument using two-color analysis to produce 2-D histograms, as well as 1-D histograms of each florescence channel. The results were calculated and presented as fluorescence intensity (mean $\pm \mathrm{SEM})$.

Immunofluorescence analysis. The immunofluorescence expression of Lewis antigens was detected following the protocol previously described with some minor modifications $(16,17)$. After 'standard' $\alpha$-L-fase-treatment, MDA-MB-231 cells were grown on glass cover-slips for $24 \mathrm{~h}$; cells were fixed in $1 \%$ paraformaldehyde/PBS for $20 \mathrm{~min}$, and blocked 
in $2 \%$ normal bovine albumin and $0.1 \%$ Tween-20 in PBS, for $1 \mathrm{~h}$, at room temperature. Cells were then incubated overnight, at $4^{\circ} \mathrm{C}$, with either biotin-conjugated Ulex europeans agglutinin $\mathrm{I}$ or $\mathrm{mAb}$ against sialyl Lewis $\mathrm{X}, \alpha_{\mathrm{v}}$ integrin or $\beta_{1}$ integrin subunits. After three washes in PBS, secondary antibodies including Alexa 647 goat anti-mouse IgG, Alexa 647 anti-mouse IgM and streptavidin conjugated with Alexa Fluor 488 (Molecular Probes) were diluted in the blocking solution and incubated with the cells, for $1 \mathrm{~h}$, at room temperature, in the dark. Cells were washed a final three times in PBS, mounted, and images captured via an Olympus immunofluorescence microscope at appropriate wavelengths.

Static adhesion assay. Ninety-six-well culture plates were coated with Hubiogel $(0.64 \mu \mathrm{g} / \mu \mathrm{l})$, collagen I $(1 \mathrm{mg} / \mathrm{ml})$, hyaluronic acid $(1 \mathrm{mg} / \mathrm{ml})$, laminin $(5 \mu \mathrm{g} / \mathrm{ml})$, or fibronectin $(1 \mu \mathrm{g} / \mathrm{ml})$ as previously described (18). MDA-MB-231 cells were subsequently harvested and treated with $\alpha$-L-fase or PBS. Cells $\left(1 \times 10^{4}\right)$ were plated onto pre-coated wells. The number of adhered cells was determined following the protocol of Rusciano et al (19). Specifically, cells were left to adhere for defined times and the wells were then washed with PBS for 3 times and subsequently fixed with $4 \%$ paraformaldehyde for $30 \mathrm{~min}$. Adherent cells were stained by $0.1 \%$ crystal violet for $15 \mathrm{~min}$ and washed with distilled water. Stained cells were solubilized in 5\% Triton X-100. Absorbance was quantitated by an ELISA plate reader at a wavelength of $570 \mathrm{~nm}$. Data were expressed as the mean of 8 -wells \pm the SEM. Additional experiments examined the stained cells directly by use of an Olympus inverted microscope with the aid of grid eyepiece (Fisher Scientific).

In blocking experiments, hyaluronic acid and HuBiogel were coated onto 96-well plates and either Km93 anti-sLeX mAb or HCAM anti-CD44 polyclonal antibody were applied to the cells in an attempt to block the specific sLe $\mathrm{X}$ and CD44 mediated interactions.

In performing the static adhesion assay on HUVECs, after $\alpha$-L-fase treatment, $5 \times 10^{3}$ of either treated or untreated MDA-MB-231 cells, suspended in $1 \mathrm{ml}$ of buffer, were seeded onto a confluent HUVEC monolayer in a 96-well plate. After the indicated times, the wells were gently washed in PBS and the adhered tumor cells were counted under the microscope with the aid of a grid eyepiece. The MDA-MB231 cells adhered on HUVECs could be easily identified by their cellular characteristics via conventional light microscopy. Data were analyzed by use of the Mann-Whitney $\mathrm{U}$ test.

Dynamic flow chamber assay. We utilized an in vitro biophysical model similar to Gomes et al to study the adhesive properties of MDA-MB-231 cells on human umbilical vein endothelial cells (HUVEC) under flow conditions (20). Specifically, after cell growth reached $80 \%$ confluence, MDA-MB-231 cells were trypsinized for 30 and $60 \mathrm{~min}$, respectively while control cells were incubated with PBS for 60 min. Cells were then diluted in HBSS (Hanks' balanced salt solution) to a final concentration of $1.0 \times 10^{6} / \mathrm{ml}$ and transferred to a 15-ml syringe. A GlycoTech (Rockville, MD) flow chamber insert and gasket were inserted into the dish cultured containing $90 \%$ confluent HUVEC cells. This formed a laminar flow chamber viewable on a conventional light microscope.

Experimental cell populations were injected into the flow chamber in Hanks' balanced salt solution at controlled physiological shear rates to maximally exclude external interference and apply quantifiable sheer stress, we used a programmable syringe pump (KD Scientific, New Hope, PA). Cells were viewed on an Axiovert 100 microscope (Zeiss Inc., Thornwood, NY) equipped with a CCD camera (Model 300T RC, Dage-MTI, Michigan City, IN). For the fluorescence-labeled experiments, $\alpha$-L-fase-treated MDAMB-231 cells were labeled with CellTrace ${ }^{\mathrm{TM}}$ Calcein Red Orange (Molecular Probes), while tumor cells in the control group were labeled with green Calcein (Molecular Probes) dye. After incubation with the fluorescence dyes, the cells were washed thoroughly in buffer. Five $\mathrm{ml}$ of each group of cells, of different fluorescent colors, were injected in to the flow chamber assays followed the procedures described above except under fluorescence microscopy. The images were recorded on sVHS videotape and the number of rolling cells with red color ( $\alpha$-L-fase treated) and green color (control) at each time interval were counted respectively by two independent observers and the results averaged.

Purified substrate coatings. To further study the adhesion of these cells under flow conditions, diluted E-selectin, $\mathrm{P}$-selectin and ICAM-1 were pre-coated on to plastic dishes following conventional procedures as described (21). Briefly, tissue culture dishes $(35 \mathrm{~mm})$ were marked with a diamond pen to circle the center. Then $25 \mu 1$ of $20 \mu \mathrm{g} / \mathrm{ml}$ protein A (Sigma) in PBS was placed in the marked area and spread with a pipette tip, incubated at $37^{\circ} \mathrm{C}$ for $1 \mathrm{~h}$ and then washed three times in PBS. Non-specific binding was blocked with $2 \%$ human serum albumin (HSA, Sigma), in PBS, for $2 \mathrm{~h}$ at $4^{\circ} \mathrm{C}$, followed by 3 washes in PBS. The marked areas were then coated with $50 \mu \mathrm{l}$ of purified substrate $(25 \mu \mathrm{g} / \mathrm{ml}$ recombinant human ICAM-1/Fc chimera, $5 \mu \mathrm{g} / \mathrm{ml}$ recombinant human E-selectin/Fc chimera or $0.5 \mu \mathrm{g} / \mathrm{ml}$ recombinant human $\mathrm{P}$-selectin/Fc chimera). All purified coatings were obtained from R\&D Systems (Minneapolis, MN).

Image analysis. As noted above, for direct counting, video was recorded onto sVHS videotapes (SONY Premium grade), and the number of cells undergoing rolling during selected time intervals were counted by two independent observers. For computer-aided image analysis, selected sequences, 3 min in length, were digitized as TIF files using the Perception video editing package (Perception PVR-2500, Digital Processing Systems, Markham, Ontario, Canada). Digitized video images were examined frame-by-frame to determine the numbers of cells rolling on endothelium and the numbers of cell arrests (complete stops). To calculate the sheer stress of individual cells, the flow course of a specific cell in one frame was recorded in log file by MetaMorph software (Universal Imaging Corp., Downingtown, PA). Briefly, when a new object appeared in the image frame (coming into the field of view, either rolling or in flowing solution) they are identified as cells, assigned a number, and tracked. Processing included application of exclusion criteria 
A

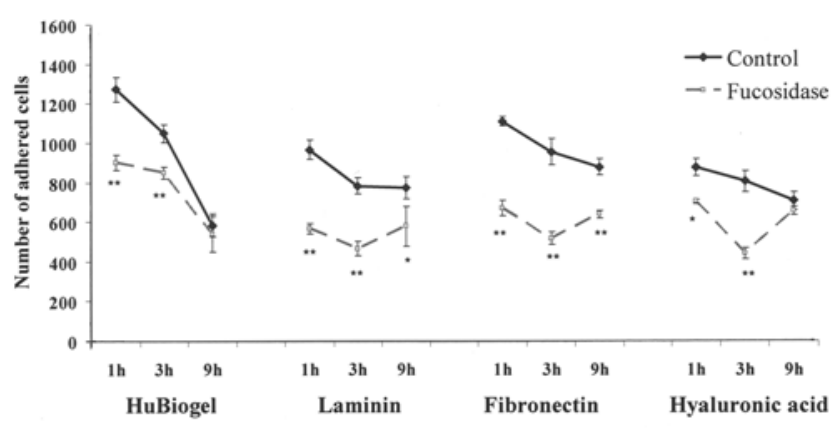

B

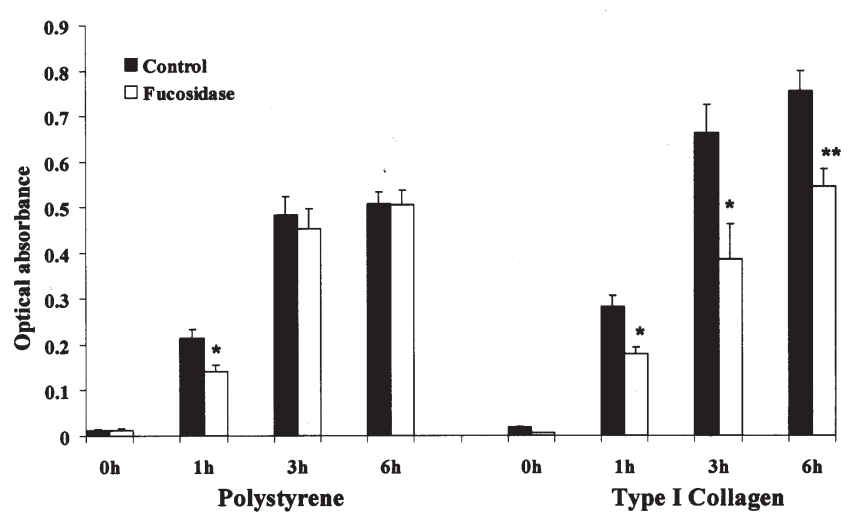

C

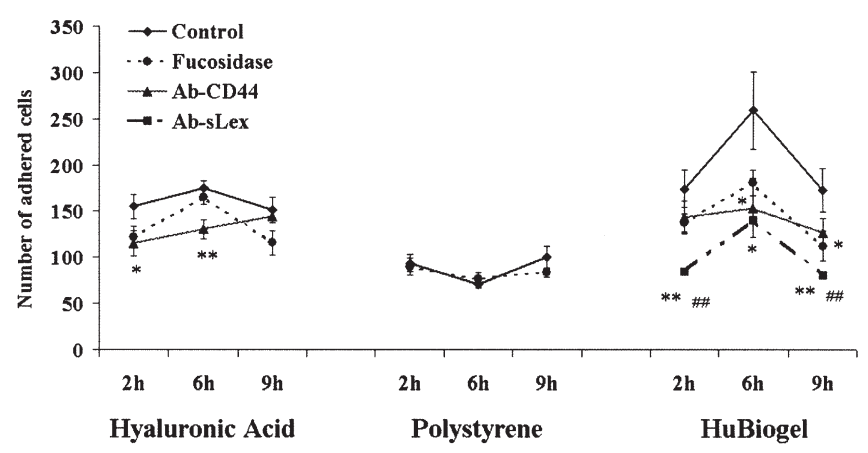

Figure 1. (A) Time-course static adhesion assay of $\alpha$-L-fase treated MDA-MB-231 cells on extracellular matrices. Defucosylation significantly decrease the adhesion of MDA-MB-231 cells to fibronectin and laminin at all three time points after treatment $(1,3$ and $9 \mathrm{~h})$. The adhesion on HuBiogel and hyaluronic acid also showed a significant decrease at 1 and $3 \mathrm{~h}$. Data are expressed as the mean \pm SE of 8 -wells. ${ }^{*} \mathrm{p}<0.05 ;{ }^{* *} \mathrm{p}<0.01$ by the Mann-Whitney U test. (B) Time-course static adhesion assay of $\alpha$-L-fase treated MDA-MB-231 cells on polystyrene and type I collagen. Defucosylation impaired cell adhesion onto type I collagen, while adhesion was unaffected on plastic surfaces. Data were expressed as the mean \pm SE of 8-wells. ${ }^{*} \mathrm{p}<0.05 ;{ }^{* *} \mathrm{p}<0.01$ by the Mann-Whitney U test. (C) Static adhesion assay of MDA-MB-231 cells on hyaluronic acid, polystyrene or HuBiogel in the presence or absence of $\alpha$-L-fase or CD44 or sLe X antibodies. The adhesion of tumor cells on HuBiogel was significantly decreased by $\alpha$-L-fase treatment, and binding of the sialyl Lewis X glycan structure decreased adhesion on hyaluronic acid and HuBiogel. Data were analyzed by the Mann-Whitney $U$ test. ${ }^{*} \mathrm{p}<0.05,{ }^{* *} \mathrm{p}<0.01$ where the $\alpha$-L-fase treated group was compared to the untreated control. ${ }^{\#} \mathrm{p}<0.05$ and ${ }^{\# \#} \mathrm{p}<0.01$ where groups were compared treated with different antibodies.

based on area and velocity to discard cell doublets, objects too small to be cells, etc. The remaining cell tracks were processed to produce instantaneous velocity plots and average cell velocity histograms. Results are expressed as means \pm SEM and analyzed using the Excel Student's t-test (Microsoft, Seattle, WA).

Data analysis. As noted, data were analyzed by Excel ${ }^{\circledR}$ (Microsoft, Seattle, WA) and SPSS ${ }^{\circledR}$ (SPSS Inc., Chicago, IL). The statistical analysis of non-Gaussian distributed data was performed by using standard non-parametric tests, primarily the Mann-Whitney U test. A paired 2 samples t-test was also used where appropriate. A p-value of $<0.05$ was considered statistically significant.

\section{Results}

$\alpha$-L-fucosidase decreases MDA-MB-231 cells adhesion to extracellular matrix components. To investigate the effect of $\alpha$-L-fase treatment on the adhesion of MDA-MB-231 tumor cells to the ECM, we first performed static adhesion assays by culturing MDA-MB-231 human breast cancer cells onto several purified ECM components; specifically type I collagen, fibronectin, laminin and hyaluronic acid. All these ECM components have previously been shown to contribute to mammary cell attachment and spreading. We found that defucosylation by $\alpha$-L-fase significantly decreased the adhesion of these cells to all simple matrices tested at the early time points but this effect was diminished or absent by $9 \mathrm{~h}$ (Fig. 1A) suggesting cellular glycosylation machinery can rapidly reconstitute $\alpha$-L-f on cell surfaces. The adhesion to HuBiogel, a reconstituted human ECM complex containing these same (and other, principally type IV collagen) components, followed the same pattern (Fig. 1A). In contrast, the adhesion to non-native matrix (polystyrene) did not show these significant changes (Fig. 1B) suggesting fucosylation does not play a significant role in the adhesion of tumor cells to a tissue culture plastic interface, while affecting the adhesion to physiologic bio-active matrices. This same trend was present with other human breast cancer cells tested (data not shown).

In a separate set of experiments, we compared the adhesion of MDA-MB-231 cells to plastic, hyaluronic acid and HuBiogel, in the presence or absence of antibodies directed against either CD44 or sLe X. Both HCAM-1, a rabbit anti-human CD44 polyclonal antibody and Km93 a mouse anti-human SeL X mAb were found to block adhesion, whereas this effect was not seen in the cells growing on plastic alone. Thus, the Sle X glycan structure appears to be involved in this adhesive process (Fig. 1C).

Defucosylation decreases the colocalization of fucose with $\beta_{1}$ integrins on MDA-MB-231 cells. In order to determine if integrins were one of the $\alpha$-L-f containing targets on MDAMB-231 cell surfaces, cells were grown on coverslips for $24 \mathrm{~h}$, fixed in paraformaldehyde/PBS, and after blocking were then incubated overnight, at $4^{\circ} \mathrm{C}$, with biotin-conjugated Ulex and monoclonal antibodies against both $\alpha_{\mathrm{v}}$ integrin and $\beta_{1}$ integrin subunits followed by incubation with green and red fluorescence labeled secondary antibody and streptavidin, respectively. The orange immunofluorescence co-localization images of either $\beta_{1}$ or $\alpha_{v}$ integrin with $\alpha-\mathrm{L}-\mathrm{f}$ were captured by microscopy. Fig. 2A demonstrates the immunofluorescence 
A

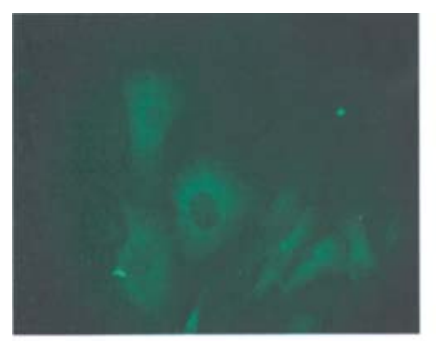

$\beta_{1}$ Integrin

B

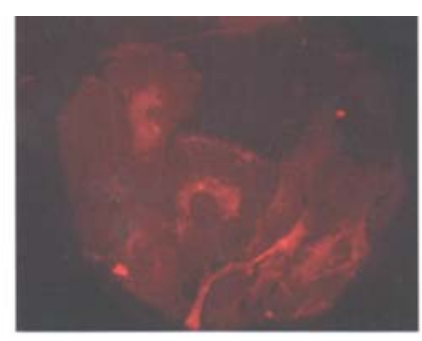

$a-L-f$

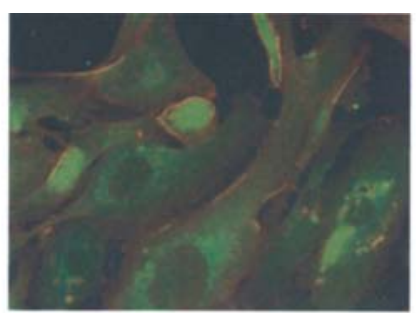

Length of Colocalization Regions

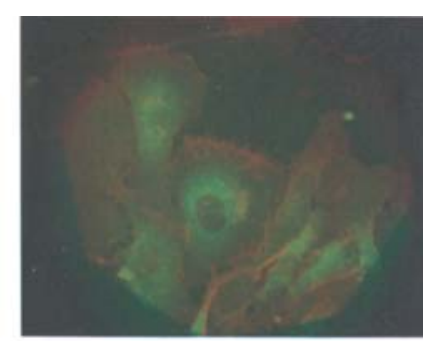

Merged $\beta_{1}$ Integrin $+a-L-f$

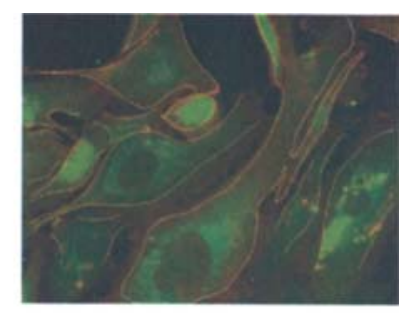

Perimeter Measure of All Cells
C

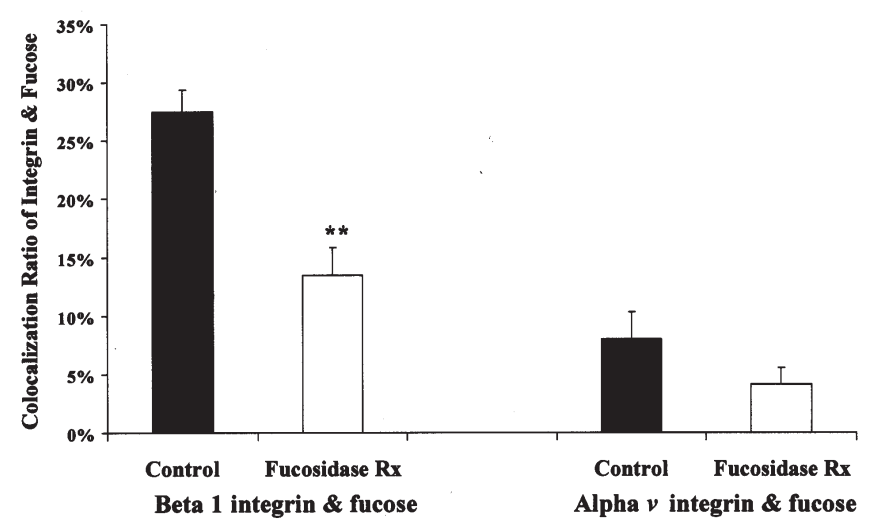

and colocalization of $\beta_{1}$ integrin and $\alpha$-L-f. The length of the co-localized segments and the perimeter of the contours were determined and the ratio of co-localization to all recognizable signals in 10 random fields were calculated by Image J (NIH) software (Fig. 2B). Fig. 2C highlights, in bar graph form, the significant decreased co-localization of $\beta_{1}$ intergrin and $\alpha$-L-f in the presence of $\alpha$-L-fase. This change was not noted in parallel experiments with $\alpha_{v}$ integrin subunits.

$\alpha$-L-fucosidase treatment also decreases sialyl Lewis $X$ expression on MDA-MB-231 tumor cells. Previously, we have shown that $\alpha$-L-fase could effectively decrease the expression of $\alpha$-L-f on multiple breast cancer cell lines including MDAMB-231 (22). As sLe X [NeuAc $\alpha 2,3$ Gal $\beta 1,4$ (Fuc $\alpha 1,3$ ) GlcNAc] is an $\alpha$-L-f-containing tetrasaccharide glycan known to be critical for tumor cell rolling/adhesion in the vascular tree, we believed it would be rational to test whether defucosylation altered the level of sLex expression on breast tumor cells. Thus, we used an indirect flow cytometry method to study the effect of $\alpha$-L-fase on sLe X expression. As was predicted, defucosylation significantly decreased
Figure 2. (A) Co-localization of integrin subunits with $\alpha-\mathrm{L}-\mathrm{f}$. After standard $\alpha$-L-fase treatment, MDA-MB-231 cells were grown on coverslips for $24 \mathrm{~h}$; cells were then fixed in paraformaldehyde/PBS, and blocked with bovine albumin and Tween-20 in PBS. Cells were then incubated overnight, at $4^{\circ} \mathrm{C}$, with biotin-conjugated Ulex, monoclonal antibodies against $\alpha_{\mathrm{v}}$ integrin and $\beta_{1}$ integrin subunits. Co-localization is identified by yellow-orange signals along the cell membranes. (B and $\mathrm{C}$ ) Illustration of the methods to determine the extent of co-localization of integrin subunits with $\alpha$-L-f. The immunofluorescent co-localization images of either $\beta_{1}$ integrin with $\alpha$-L-f or $\alpha_{\mathrm{v}}$ integrin with $\alpha$-L-f were captured by fluorescence microscopy. The length of the co-localized segments and the perimeter of the cell contours were measured by Image $\mathbf{J}(\mathrm{NIH})$ software. The co-localization ratio was expressed as the ratio of the length of positive co-localization segments to the sum of the perimeters of all recognizable cell contours. The colocalization ratios from 10 fields were calculated for each group. ${ }^{* *} \mathrm{p}<0.01$ by the Mann-Whitney U test.

FL1-H FITC (a surrogate marker for sialyl Lewis X fluorescence intensity) (Fig. 3A). By using the 'events above the gate method' (representing the number of immunoreactive cells) the $\alpha$-L-fase treated group sharply segregated from the control group (Fig. 3B), highlighting the decreased reactivity. The 'negative' control showed only a low background signal.

$\alpha$-L-fucosidase treatment decreases the static adhesion of MDA-MB-231 cells to human umbilical vein endothelium cells. We have identified that the static adhesion of MDAMB-231 cells to endothelium in vitro is inhibited by $\alpha-\mathrm{L}-$ fase treatment. The adhered MDA-MB-231 cells on HUVECs could be identified by their different cytomorphologic features (Fig. 4A), which made it possible to quantitatively measure the adhesion of these tumor cells on endothelium in vitro. To verify the results obtained in Fig. $1 \mathrm{C}$ as to the importance of sLe $\mathrm{X}$ in modulating these processes, we also examined the effect of adding a sLe $\mathrm{X}$ specific antibody into the adhesion assay system. In verification of these earlier findings, the Km93 anti-sLe $X$ antibody also significantly inhibited the 
A

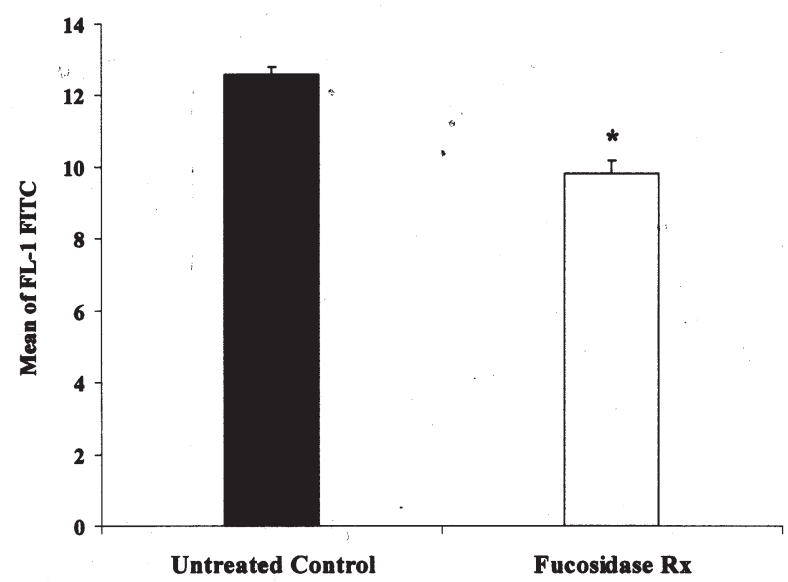

B

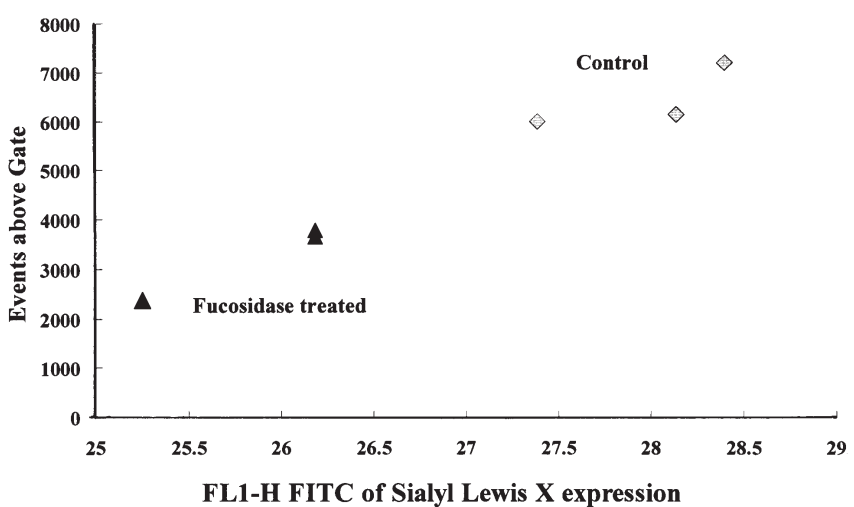

C

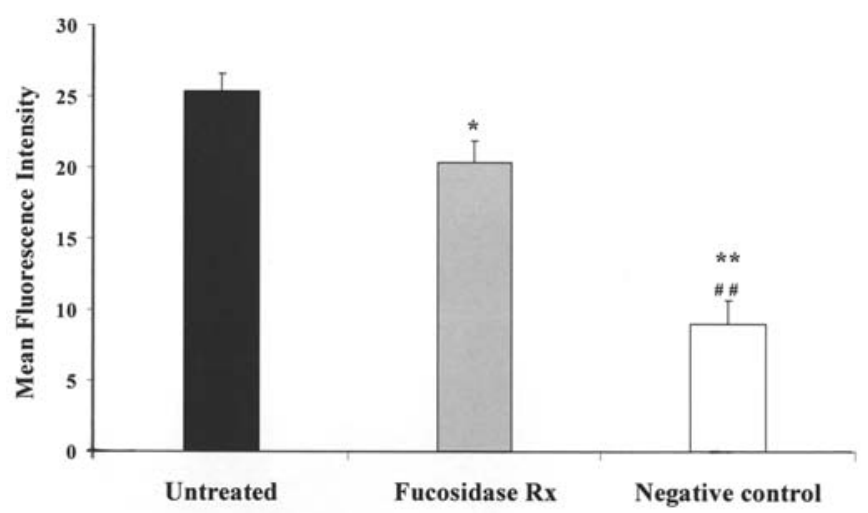

Figure 3. (A and B) Flow cytometry analysis of sialyl Lewis X glycan on MDA-MB-231 cells. $\alpha$-L-Fase treatment significantly decreased the levels of sLe X. (A) The mean intensity of sLe X FL-1 FITC is shown. " $\mathrm{p}<0.05$ by the Mann-Whitney $U$ test. The difference in median intensity was similarly significant. (n=3). (B) The 'Events-above Gate' of sLe X utilizing FL1-H FITC. (C) Immunofluorescence of sialyl Lewis X. MDA-MB-231 cells treated with or without $\alpha$-L-fase were grown on cover-slips, fixed in paraformaldehyde, blocked with BSA and then incubated overnight at $4^{\circ} \mathrm{C}$ with $\mathrm{Km} 93 \mathrm{mAb}$ against sLe $\mathrm{X}$ followed by fluorescent-conjugated secondary antibodies. Images were captured and Image J (NIH) software was used to measure the fluorescent intensity of 9 random fields from each group. Data were analyzed by the Mann-Whitney $U$ test. ${ }^{*} \mathrm{p}<0.05$ where the $\alpha$-L-fasetreated group was compared to the untreated control group. ${ }^{* *} \mathrm{p}<0.01$ where the auto-fluorescent (negative-control) group was compared to the untreated control group. There was also a significant difference $(\# \#)<0.01)$ where the auto-fluorescent group was compared to the $\alpha$-L-fase-treated group.
A

HUVEC

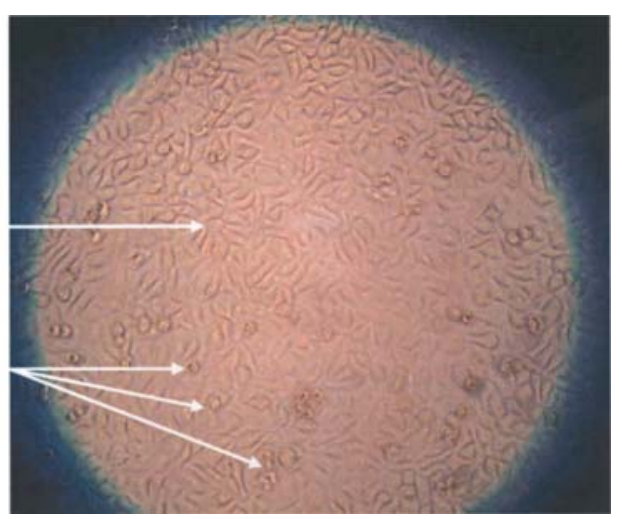

B

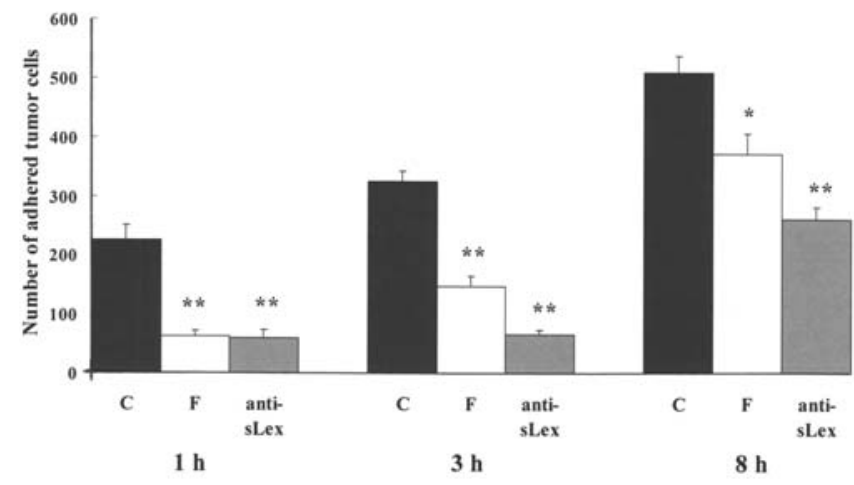

Figure 4. (A) Static adhesion assay testing of MDA-MB-231 cells on HUVEC. $\alpha$-L-fase treated and untreated cells $\left(5 \times 10^{3} / \mathrm{ml}\right)$ were seeded on to a confluent HUVEC monolayer cultured in a 96-well plate. After the indicated times, the wells were washed in PBS and the adhered tumor cells counted. The adhered MDA-MB-231 cells displayed a different morphology from the HUVECs as indicated by the arrows and could be easily identified and quantified. (B) Defucosylation significantly decreased the MDA-MB-231 cell adhesion on HUVECs under static conditions. Km93 anti-sLe X antibody also significantly inhibited the adhesion of the tumor cells on endothelial cells. Data were analyzed by the Mann-Whitney U test. " $p<0.05$; ** $<<0.01 ;(\mathrm{C})$, untreated control; (F), the $\alpha$-L-fase-treated group.

adhesion of the tumor cells on endothelial cells (Fig. 4B). This stimulated us to move to a more rigorous system mimicking the in vivo state, i.e. use of a dynamic flow chamber system.

$\alpha$-L-fucosidase treatment decreases the rolling of MDA-MB231 tumor cells on endothelium under flow conditions. The rolling of tumor cells on endothelium is an essential step in extravasation during hematogenous metastasis to form distant foci. Similar to leukocytes, the initial interaction between tumor cells and endothelium appears to be mediated by sLe X glycan and E-selectin. As defucosylation removed $\alpha$-L-f from Lewis antigens and decreased the expression of sLe x (Fig. 3), we sought to determine if this treatment would lead to changes in the rolling behavior of defucosylated tumor cells. Thus, a flow chamber assay system were used to study the interaction between tumor cells and endothelium under flow condition (sheer stress), providing better mimicking of the in vivo situations as compared with its static counterpart. 
A

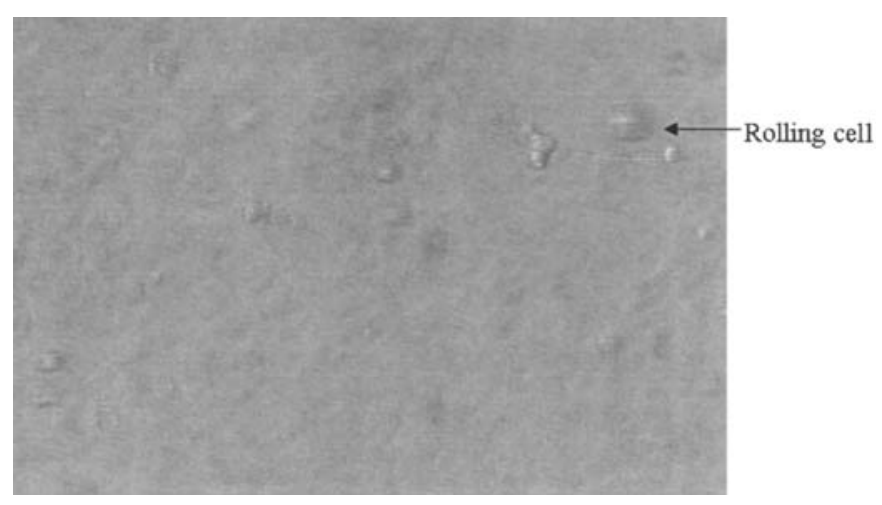

B

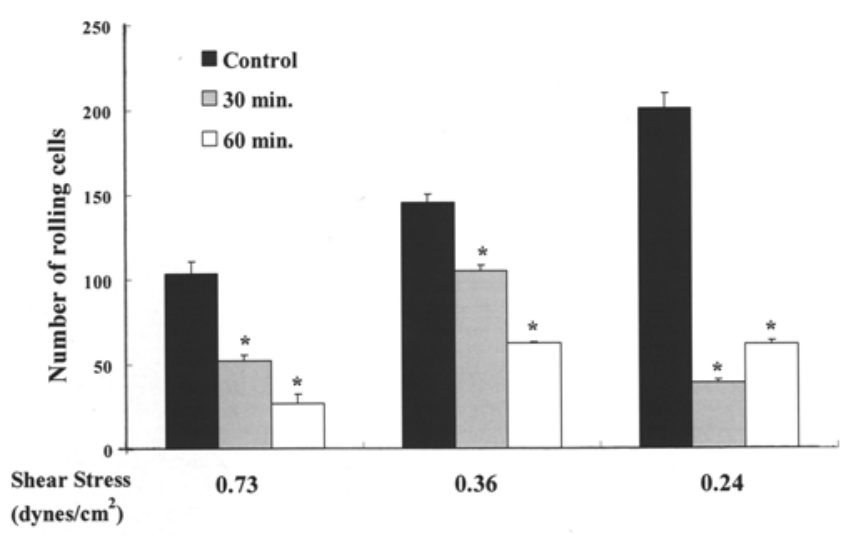

C

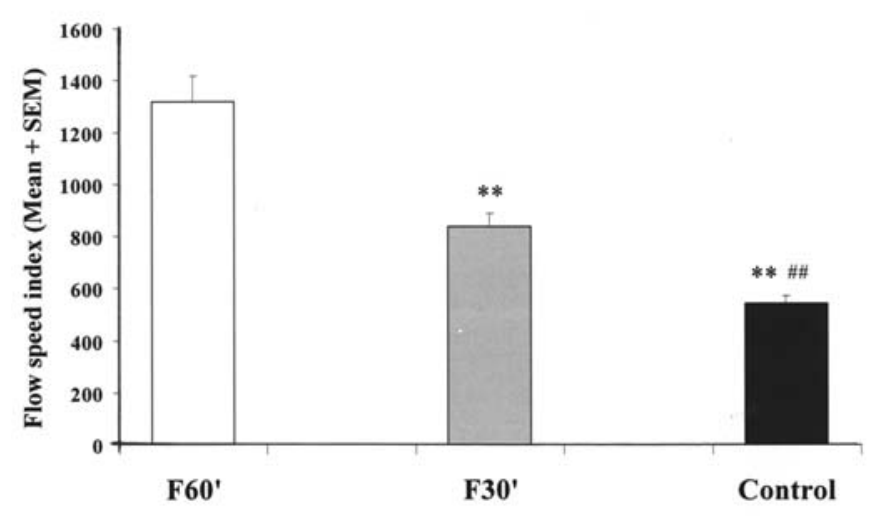

D

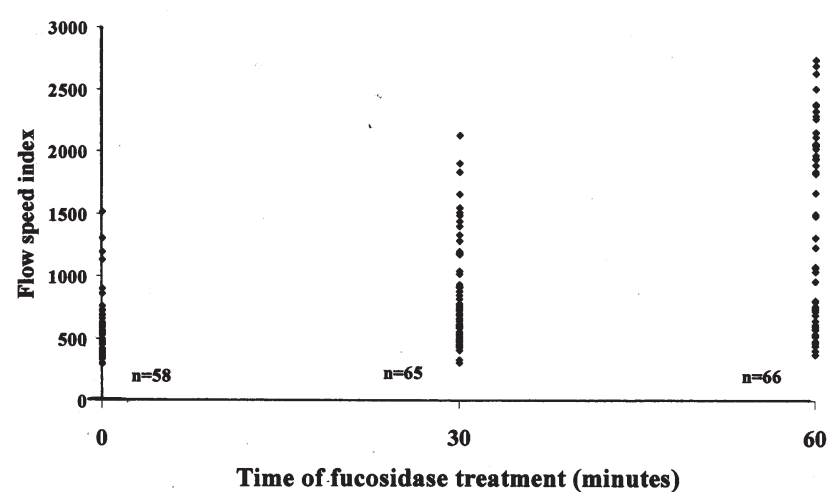

In the first experiment, we used non-labeled MDA-MB231 breast tumor cells and HUVECs to investigate the effects
$\mathbf{E}$

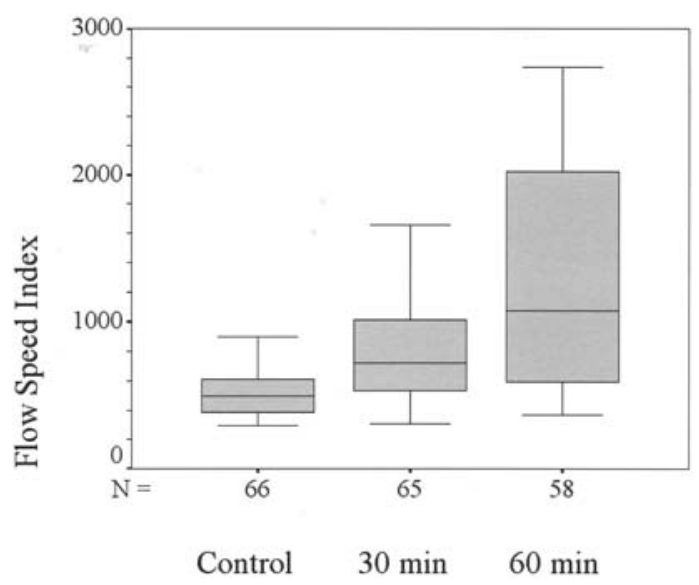

Figure 5. (A) A representative image captured from the dynamic flow chamber assay. MDA-MB-231 cells were trypsinized, counted and evenly sorted into 3 groups. Two groups were treated with $\alpha$-L-fase, at $37^{\circ} \mathrm{C}$ for 30 or $60 \mathrm{~min}$, respectively. The control cells were incubated with only PBS for $60 \mathrm{~min}$. Cells were injected into the flow chamber in HBSS at controlled physiological shear rates using a programmable syringe pump. Cells were viewed on an Axiovert 100 microscope. (B) Flow chamber assay disclosed a significant decrease of MDA-MB-231 cells rolling on HUVEC after $\alpha$-Lfase treatment. The number of tumor cells rolling on HUVEC (shear stress) was found to decrease under three different flow speeds and time $\left({ }^{*} \mathrm{p}<0.05\right.$ by the Mann-Whitney U test), for all three flow speeds. There was also a significant difference between 30 and 60 min of treatment $(p<0.05$ by the Mann-Whitney U test). (C) The effect of $\alpha$-L-fase on tumor cells flow speed on HUVEC. Defucosylated cells flowed faster than untreated control cells. The shear stress of the MDA-MB-231 cells significantly increased with time. ${ }^{* *} \mathrm{p}<0.01$ by the Mann-Whitney $U$ test). There was also a significant difference between 30 and $60 \mathrm{~min}$ of treatment ( ${ }^{\# \#} \mathrm{p}<0.01$ by the MannWhitney U test). (D) The distribution of the flow speed of MDA-MB-231 cells after $\alpha$-L-fase treatment. The cells flowed faster (shear stress decreased) after defucosylation. This was correlated with the time of treatment with $\alpha$-Lfase. (E) Box-plot of the flow speed of MDA-MB-231 cells after $\alpha$-L-fase treatment. In the box plot, the box stretches from the lower hinge (defined as the 25 th percentile) to the upper hinge (the 75 th percentile) and offers a different representation of the data shown above.

of defucosylation on the tumor cell adhesion on endothelium under flow conditions (Fig. 5A). We also use automated computer analysis as well as algorithms developed in conjunction with commercial software programs. The combination of large amounts of image data and automated processing made it practical to analyze a sufficient number of events to accurately calculate mean velocities, quantify acceleration events, and determine statistical significance.

The assay disclosed a significant decrease in the number of MDA-MB-231 cells rolling on HUVEC after $\alpha$-L-fase treatment under three different shear stress conditions, and compared with the standard 30 min of treatment, demonstrated that increasing treatment times caused a decrease of rolling on HUVEC cells (Fig. 5B). The effect of $\alpha$-L-fase on tumor cell flow speed on HUVEC cells was also examined. As was predicted, as the defucosylated cells had a weaker adhesion to the HUVEC cells, these cells flowed faster as compared to the untreated control cells and this sheer stress continued to significantly increase with more extensive exposure to $\alpha$-L-fase (Fig. 5C). This change was appreciated more easily when a scattergram of the flow speed of the MDA-MB-231 cells after $\alpha$-L-fase treatment was plotted (Fig. 5D) along with a box-plot of the same data (Fig. 5E). 
A
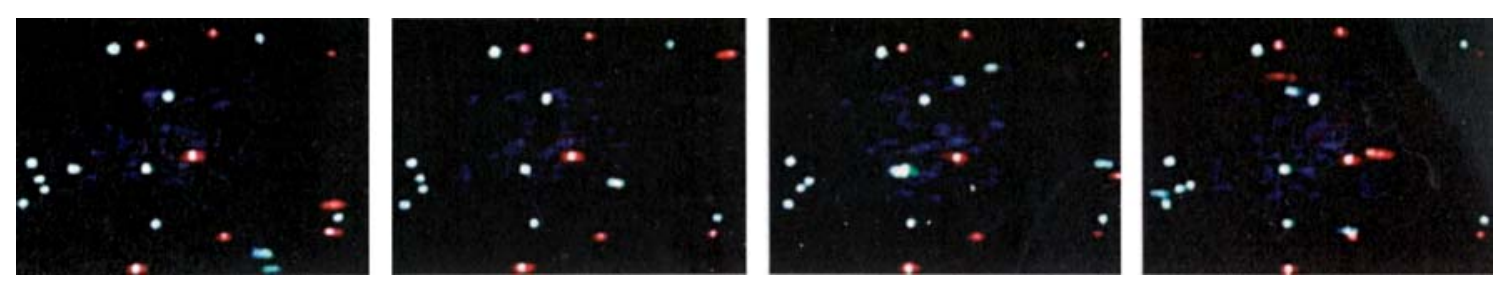

B

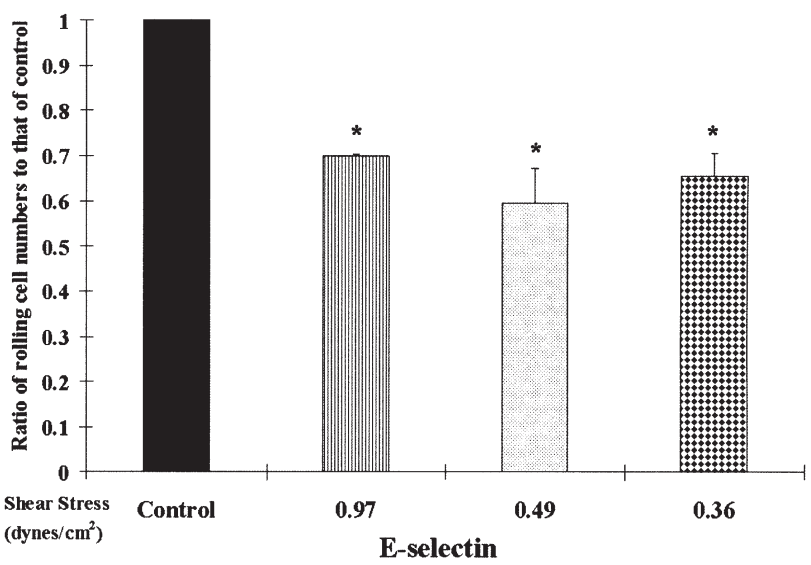

C

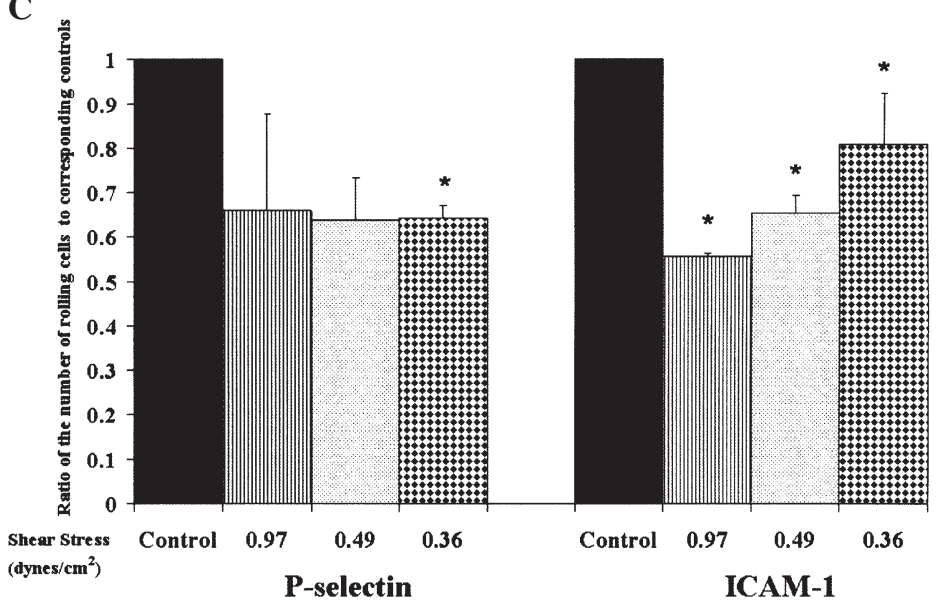

Figure 6. (A) Consecutive images captured from a representative flow chamber assay. Each dot is an individual labeled MDA-MB-231 cell. Tissue culture dishes were coated with purified substrates as described in the text. $\alpha$-L-fase treated MDA-MB-231 cells were labeled with CellTrace Calcein Red Orange, while cells in the control group were labeled with Calcein green. After incubation, the mixtures of cells with different colors were injected to the flow chamber and video recorded under fluorescence microscopy. The number of rolling cells at various time intervals were counted. (B and C) Fluorescentlabeled flow chamber assay on purified adhesion molecules. (B) E-selectin, (C) P-selectin and ICAM-I. $\alpha$-L-fase treatment decreased the rolling of MDAMB-231 cells on all three adhesion molecules at various flow speeds. Data were analyzed by the Mann-Whitney $\mathrm{U}$ test. ${ }^{*} \mathrm{p}<0.05,{ }^{* *} \mathrm{p}<0.01$.

In the box plot, the box stretches from the lower hinge (defined as the 25 th percentile) to the upper hinge (the 75 th percentile); median, minimum and maximum are also displayed.

$\alpha-L$-fucosidase treatment decreases the rolling of $M D A-M B$ 231 on E-selectin, P-selectin and ICAM-I. To further study the effects of $\alpha$-L-fase on tumor-ECM interactions, we sought to study the effect of defucosylation on mammary tumor cells rolling under more simplified, better defined conditions in the flow chamber. Thus, labeled E-selectin, P-selectin or ICAM-I was used to coat flow chamber plates and labeled cells could be easily differentiated by their different colors under fluorescence microscopy (Fig. 6A). The variance in the number of rolling cells revealed different interactions with individual components. Again, there were alternations dependent upon flow speed. However, a unifying principle was that $\alpha$-L-fase treated MDA-MB-231 cells displayed impaired rolling, on E-selectin and ICAM-1, when compared to untreated controls (Fig. 6B). This, thus, provided evidence to support the hypothesis that modification of a single $\alpha$-L-f containing monosaccharide modifies complex interactions between tumor cells, the ECM and endothelium.

\section{Discussion}

Breast cancer is the most frequently diagnosed cancers in American women with approximately one third of all American cancer cases being of mammary gland origin, in this gender (23). Metastases are the major cause of morbidity and mortality. Patients with localized disease have a 5-year survival rate approaching 98\%; in contrast, the survival rate drops to $26 \%$ in those patients having distant metastases at diagnosis (23). Thus, early detection and intervention to deter tumor progression are pivotal to improve the prognosis of patients with breast cancer.

Alterations in the number and composition of glycosylation events are closely correlated with malignant transformation, tumor progression and poor prognosis $(2,24)$. Abnormal glycosylation patterns further signal the transformation of breast cancer to a metastatic phenotype (25). In previous studies, we found high levels of $\alpha$-L-f expression on human breast cancer cell surfaces including the MDAMB-231 cell line and presented evidence that this appeared to correlate with its known highly metastatic potential (22). $\alpha$-L-f-containing glycans are known to participate in many physiological processes, i.e., constituting blood group antigens, mediating leukocyte-endothelial adhesion, fertilization and ontogenesis differentiation (26). The importance of fucosylation has been further demonstrated by rare genetic diseases where it was known to be altered. Among these entities are leukocyte adhesion deficiency (LAD) type II, in which the terminal fucose moieties are severely impaired, leading to a profound defect in leukocyte rolling on endothelium (27). Similarly, in 1,3-fucosyltransferase IV and VII double-mutant mice, diminished fucose expression on cell surfaces lead to the absence of rolling of lymphocytes on high endothelial venules (28). The 
level of fucosylation has also been found to be altered in various tumors while the up-regulated expression of the fucosyltransferase VII gene has been shown to correlate with lymph node metastasis and poor prognosis in patients with breast cancer (29).

In this study, we sought to explore the effects of enzymatically down-regulating the expression of $\alpha$-L-f on a representative, well characterized, human breast cancer cell line in vitro. Fucosidases are the major lysosomal glycosidases that catalyze the removal of fucose residues from complex molecules. $\alpha$-L-fucosidase (E.C. 3.2.1.51), hydrolyzes the glycosidic bonds in $\alpha-1,2-, \alpha-1,3-, \alpha-1,4-$ and $\alpha-1,6-\mathrm{L}$-fucose linkages (30). High serum $\alpha$-L-fase activity has been associated with distant metastasis and recurrence of colorectal cancer (31), while low activity of fucosidase has been found in hepatocellular carcinoma (32). These somewhat contradictory observations may reflect an inadequate hostfeedback mechanism to regulate the 'fucose-burden' in serum and in tissue, respectively.

Here, we hypothesize that reducing the 'fucose-burden' by exogenous fucosidase would interfere with tumor functions modulated by fucosylated glycans and glycoproteins. Exogenous glycosidases have been widely used to modify the composition of cell surfaces and 'debulking' $\alpha-\mathrm{L}-\mathrm{f}$ by a direct biochemical approach would presumably be more clinically practical than genetic manipulation. Previously, we found down-regulation of $\alpha$-L-f and sLe $\mathrm{X}$ did not altered the rate of either cell growth or colony formation in the MDA-MB-231 cells (22), suggesting defucosylation was not cytotoxic. Here, we demonstrate that this manipulation does impair crucial cell-ECM interactions and presumably subsequent cell signaling, which leads to alterations in tumor function and behavior.

In this study, we have identified significant changes in the adhesion properties of defucosylated human breast cancer cells. Under static conditions, the adhesion of MDAMB-231 cells on simple ECM components (fibronectin, laminin, type I collagen and hyaluronic acid) and complex matrices (HuBiogel) were significantly decreased by $\alpha$-L-f ase treatment. By the nature of the exposure and the relatively ubiquitous nature of $\alpha$-L-f-containing molecules on tumor cell surfaces, the defucosylation effects most assuredly interfered with the functions of many fucosylated adhesion molecules expressed on these cells. Phenotypically, this resulted in a general impairment of adhesion on various matrix components. Similar to our findings, others have shown that manipulating enzymes that affect global cellular fucosylation results in an altered interaction of cancer cells with ECM components such as fibronectin (33).

Several reports have also suggested that glycosylation modulates the function of integrins. Alteration of glycosylation on integrins notably affects the ability of cells to adhere to fibronectin and laminin-1 (34). It is already known that $\beta 1-6$ branched glycosylations carried by $\beta_{1}$ and $\alpha_{3}$ integrin subunits on metastatic human melanoma cells modulates the adhesive abilities of these tumor cells by affecting the ligand binding properties of the $\alpha_{3} \beta_{1}$ integrins (35). Integrin receptors for fibronectin on the MDA-MB-231 cells contain the $\beta_{1}$ subunit and anti- $\beta_{1}$ antibody has previously been found to inhibit the adhesion and migration of MDA-MB-231 to fibronectin (36). In our studies, we found decreased colocalization of $\alpha-\mathrm{L}-\mathrm{f}$ with the $\beta_{1}$ integrin subunit, but not with $\alpha_{v}$ integrin. The decreased fucosylation associated with $\beta_{1}$ integrin most probably contributed to the altered tumor adhesion on fibronectin and other matrix components. It is also probable that $\alpha$-L-fase treatment modified other cell surface adhesion molecules, such as the Lewis X structures. Furthermore, high amounts of $\alpha$-L-f have been found on the CEA-related cell adhesion 1 molecule (37). Similar to $\alpha$-L-f's role on the $\beta_{1}$ integrins in our study, the hypersialylation of $\beta_{1}$ integrins in colon adenocarcinoma upregulated attachment to both collagen type I and laminin in work reported by others (38).

In addition to decorating adhesion molecules, oligosaccharides are also key constituents of carbohydrates. Sialyl Lewis X (sLe X), an $\alpha$-L-f-containing tetrasaccharide, is the major ligand for the selectins, mediating the rolling of various cells on endothelium. The sLe $\mathrm{X}$ antigen is characteristically expressed in aggressive cancers and in more advanced stages of neoplastic progression asociated with invasion and metastasis. Normal, non-transformed breast epithelial cells do not express sLe X or sLe A while the epithelial expression of these oligosaccharide epitopes has been shown to be enhanced in primary breast carcinoma lesions and further up-regulated in patients who have metastatic disease. The expression of P- and E-selectin has also been shown to be greatly enhanced in tumor-bearing tissues as compared to their normal counterparts (39). The cytosolic form of sLe $\mathrm{X}$ has been found to be elevated in cancerous tissue in general, and serum sLe $X$ and soluble E selectin elevated in patients with advanced and recurrent breast cancer, especially in those with distant metastases (40). Elevated expression of Lewis antigens, including sLe $\mathrm{X}$ in primary breast cancer tissues, has been found to correlate with both lymph node metastases and poor prognosis (41). Others have also shown that compared to primary tumors, metastatic breast cancer cells isolated from bone marrow expresses higher amounts of Le X, sLe X and Lewis Y (42). The prominent role of sLe $\mathrm{X}$ in the metastases of breast cancer, having been established through these studies, motivated us to investigate the effects of defucosylation on the $\alpha$-L-f containing sLe $X$.

By using flow cytometry, we identified significantly decreased expression of sLe $X$ on the cell surface of MDA-MB-231 cells following treatment with $\alpha$-L-fase. Previously this strategy was reported to completely abolish the recognition of this antigen by a Lewis X-specific antibody (43). Presumably, the epitope of sLe X, recognized by the $\mathrm{mAb} \mathrm{Km93,} \mathrm{was} \mathrm{destroyed} \mathrm{by} \mathrm{hydrolysis} \mathrm{of} \mathrm{the} \mathrm{terminal}$ fucose. We also found that the sLe $\mathrm{X}$ antibody interfered with the adhesion of tumor cells to the complex ECM. Recently, it has been reported that sLe X may directly participate in epithelial migration and repair (44). Thus, the functional role(s) of sLe X in mediating adhesion is probably much more complex that simply its regulation of cell rolling on endothelium.

Genetically manipulating $\alpha-\mathrm{L}-\mathrm{f}$ and sLe $\mathrm{X}$ expression also influences the interaction between circulating cells and endothelium. $\alpha-1,3$-fucosyltransferase-VII-deficient cells are known to have a significant reduction in their 
interaction with $\mathrm{P}$-selectin and E-selectin under flow conditions in vitro (45). Furthermore, down-regulating the levels of the fucosylation generating enzyme, FX, affects global cellular fucosylation, decreases adhesion to activated endothelial cells and to recombinant E-selectin, and alteres the interaction of colorectal cancer cells with ECM components (34). Lastly, Lewis lung carcinoma cells treated with the glycosylation inhibitor, AcGnG-NM, has been seen to result in reduced expression of sLe X, impaired P-selectindependent cell adhesion in vitro and reduced formation of metastases in vivo (46).

The importance of $\alpha$-L-f in the interaction of sLe $X$ with selectins has been further shown by use of steered molecular dynamics (SMD) simulation studies. Here the intermolecular dissociation was mainly determined by separation of $\alpha$-L-f from $\mathrm{Ca}^{2+}$ ions in selectin-ligand systems (47). Removal of $\alpha$-L-f resulted in conformational changes that impaired the adhesive functionality of selectin-ligand interactions under external forces. Ramphal et al have reported that modifications of $\alpha-\mathrm{L}-\mathrm{f}$ on sLe $\mathrm{X}$ were deleterious in regards to E-selectin binding, as the replacement of the hydroxyl groups on $\alpha$-L-f by hydrogen abrogated E-selectin binding (48). More specifically, the presence of fucose at the $\alpha 1,3$-position was essential for selectin ligand function and modulated the interaction with calcium during binding with E-selectin (49), encouraging us to place the study into a more physiologically-mimicking setting.

Currently, high temporal- and spatial-resolution flow systems are capable of capturing images at high speed and resolution, which makes it possible to accurately measure an individual cell's velocity and acceleration. Utilizing tumor cells and control cells labeled with different fluorescent probes provided us an approach to study cells under flow conditions on identical matrices. By use of this technique, we have quantified the decreased rolling of defucosylated breast cancer cells on HUVEC endothelial cells in vitro. These studies revealed that under the experimental conditions, defucosylation resulted in an impaired interaction between the tumor cells and the endothelium as well as with purified E selectin, ICAM-I and P-selectin at low sheer stress.

In addition to the changes caused by sLe $X$ reduction, $\alpha$-L-f ase also affects many other $\alpha$-L-f-containing glycans . We know from other published works, for example, that highly metastatic colorectal cancer variants which have had their cellular sLe A down regulated, show decreased adhesion to endothelial cells and to recombinant E selectin (50). Sialyl fucosyl poly-N-acetylgalactosamine gangliosides also mediate E selectin-dependent rolling and tethering of cells under dynamic flow and physiologic shear stress conditions (51). Similar to our findings, Liu et al found that down regulation of sLe X decreased human hepatocarcinoma 7721 cell adhesion to HUVEC while exposure to the KM93 antibody significantly abolished the cell adhesion, migration, and invasion capabilities (15). Zhang et al using neuraminidase and $\alpha$-L-fase to remove the sialyl and fucosyl residues, respectively found that compared to sialyl residues, fucosyl residues were more important for human hepatocarcinoma cell adhesion to fibronectin and laminin but less critical to their adhesion to HUVEC. Furthermore, cell adhesion to HUVEC, migration, and invasion were all inhibited by the use of a monoclonal antibody to sLe X (52). Finally, in a reverse experiment, treatment of human cord blood cells with GDP-fucose and exogenous ( $\alpha-1-3)$-fucosyltransferase VI increased cell-surface sLe X determinants, augmented binding to P- and E-selectin, and improved cell rolling on $\mathrm{P}$ - and E-selectin under flow conditions (53).

Evidence from us and others thus argues that modifying carbohydrates and oligosaccharides results in inhibition of both cell-cell recognition and cell-matrix interactions. A clinical scenario could thus be visualized, whereby circulating carcinoma cells, immediately following a surgical intervention, were exogenously defucosylated with the stated goal of inhibiting any tumor cell interaction with endothelium in an attempt to minimize metastases. This concept is not unique to us and, in fact, potential cancer therapies by blocking carbohydrate-mediated tumor cell adhesion or interfering with glycosylation are advancing. Mimics of sLe $X$ has been designed and synthesized to inhibit cell interaction with E- and P-selectin (54). Soluble sLe X has been shown to successfully compete with cell surfacebound sLe $\mathrm{X}$ during interactions between activated endothelium and tumor cells. Along the same lines, tumor-cell arrest in the lung vasculature has been shown to be dramatically inhibited by exogenous liposomal sLe X (55). Innovative research in tumor glycobiology should continue to provide us with new weapons to deter neoplastic progression including metastasis and help to lower the mortality of patients with solid tumors in the future.

\section{Acknowledgements}

The study was supported in part by grants from the DOD (DAMD 17-99-1-9415) and the NIH [P50 CA89019; R21 AT001636, HHSN2-61200566001C (SBIR Phase II, RPF N44-CM-47041-19)] and HL62736.

Conflict of interest statement. Drs Singh and Siegal hold intellectual property rights for HuBiogel ${ }^{\mathrm{TM}}$ [U.S. Patent No. 10/546,506 (Patent Pending), International Application No. PCT/US2004/005255 (Patent Pending)] to the UAB Research Foundation. Additionally, Dr Singh is the CEO of In Vivo Biosciences, Inc., which holds the exclusive worldwide rights to market this biomaterial. All other authors have declared that they have no other real or potential conflict of interest associated with this manuscript.

\section{References}

1. Hakomori S: Glycosylation defining cancer malignancy: new wine in an old bottle. Proc Natl Acad Sci USA 99: 10231-10233, 2002.

2. Orntoft TF and Vestergaard EM: Clinical aspects of altered glycosylation of glycoproteins in cancer. Electrophoresis 20: 362-371, 1999.

3. Renkonen R, Mattila P, Majuri ML, et al: In vitro experimental studies of sialyl Lewis $\mathrm{x}$ and sialyl Lewis a on endothelial and carcinoma cells: crucial glycans on selectin ligands. Glycoconj J 114: 593-600, 1997.

4. Ringeard S, Harb J, Gautier F, et al: Altered glycosylation of alpha(s) beta 1 integrins from rat colon carcinoma cells decreases their interaction with fibronectin. J Cell Biochem 62: 40-49, 1996.

5. Leppa S, Heino J and Jalkanen M: Increased glycosylation of beta 1 integrins affects the interaction of transformed S115 mammary epithelial cells with laminin-1. Cell Growth Differ 6: 853-861, 1995. 
6. Martegani MP, Del Prete F, Gasbarri A, et al: Structural variability of CD44v molecules and reliability of immunodetection of CD44 isoforms using mAbs specific for CD44 variant exon products. Am J Pathol 154: 291-300, 1999.

7. Listinsky JJ, Listinsky CM, Alapati V, et al: Cell surface fucose ablation as a therapeutic strategy for malignant neoplasms. Adv Anat Pathol 8: 330-337, 2001

8. Thurin $\mathrm{M}$ and Kieber-Emmons T: SA-Lea and tumor metastasis: the old prediction and recent findings. Hybrid Hybridomics 21: 111-116, 2002.

9. Kannagi R: Carbohydrate-mediated cell adhesion involved in hematogenous metastasis of cancer. Glycoconj J 14: 577-584, 1997.

10. Smith RA, Saslow D, Sawyer KA, et al: American Cancer Society guidelines for breast cancer screening: update 2003. CA Cancer J Clin 53: 141-169, 2003.

11. Van 't Veer LJ, Dai H, van de Viver MJ, et al: Gene expression profiling predicts clinical outcome of breast cancer. Nature 415: 530-536, 2002.

12. Yamaguchi A, Ding K, Maehara M, et al: Expression of nm23$\mathrm{H} 1$ gene and sialyl Lewis $\mathrm{X}$ antigen in breast cancer. Oncology 55: 357-62, 1998.

13. Jeschke U, Mylonas I, Shabani N, et al: Expression of sialyl lewis X, sialyl Lewis A, E-cadherin and cathepsin-D in human breast cancer: immunohistochemical analysis in mammary carcinoma in situ, invasive carcinomas and their lymph node metastasis. Anticancer Res 25: 1615-1622, 2005.

14. Goodly LJ, Singh RK, Wang MH, et al: In vivo modulation of human tumor cell growth by normal human extracellular matrix. Tumour Biol 15: 326-336, 1994.

15. Liu F, Zhang Y, Zhang XY, et al: Transfection of the nm23-H1 gene into human hepatocarcinoma cell line inhibits the expression of sialyl Lewis X, alpha1,3 fucosyltransferase VII and metastatic potential. J Cancer Res Clin Oncol 128: 189-196, 2002.

16. Elmgren A, Mollicone R, Costache M, et al: Significance of individual point mutations, T202C and C314T, in the human Lewis (FUT3) gene for expression of Lewis antigens by the human alpha $(1,3 / 1,4)$-fucosyltransferase, Fuc-TIII. J Biol Chem 272: 21994-21998, 1997.

17. Yoshioka K, Foletta V, Bernard O, et al: A role for LIM kinase in cancer invasion. Proc Natl Acad Sci USA 100: 7247-7252, 2003.

18. Hori T, Yamashaki Y, Ohira M, et al: A novel orthotopic implantation model of human esophageal carcinoma in nude rats: $\mathrm{CD} 44 \mathrm{H}$ mediates cancer cell invasion in vitro and in vivo. Int J Cancer 92: 489-496, 2001.

19. Rusciano D, Lorenzoni P and Burger MM: The role of both specific cellular adhesion and growth promotion in liver colonization by F9 embryonal carcinoma cells. Int J Cancer 48: 450-456, 1991

20. Gomes N, Berard M, Vassy J, et al: Shear stress modulates tumor cell adhesion to the endothelium. Biorheology 40: 41-45, 2003.

21. Ni N, Kevil CG, Bullard DC, et al: Avidity modulation activates adhesion under flow and requires cooperativity among adhesion receptors. Biophys J 85: 4122-4133, 2003.

22. Yuan K, Listinsky CM, Singh RK, et al: Cell surface associated alpha-L-fucose moieties modulate human breast cancer neoplastic progression. Pathol Oncol Res (In press).

23. Cancer Facts \& Figures 2005: American Cancer Society: 2005. http://www.cancer.org/downloads/STT/CAFF2005f4PWSecure d.pdf.

24. Couldrey C and Green JE: Metastases: the glycan connection. Breast Cancer Res 2: 321-323, 2000.

25. Laidler P and Litynska A: Tumor cell N-glycans in metastasis. Acta Biochim Pol 44: 343-357, 1997.

26. Becker DJ and Lowe JB: Fucose: biosynthesis and biological function in mammals. Glycobiology 13: 41R-53R, 2003.

27. Etzioni A and Tonetti M: Leukocyte adhesion deficiency IIfrom A to almost Z. Immunol Rev 178: 138-147, 2000.

28. M'Rini C, Cheung G, Schweitzer C, et al: A novel endothelial L-selectin ligand activity in lymph node medulla that is regulated by alpha(1,3)-fucosyltransferase-IV. J Exp Med 198: 1301-1312, 2003.

29. Ding KF and Zheng S: Study on relationship of fucosyltransferase gene types in breast cancer with metastasis and prognosis. Zhonghua Wai Ke Za Zhi 42: 546-550, 2004.

30. Johnson SW and Alhadeff JA: Mammalian alpha-L-fucosidases. Comp Biochem Physiol B 99: 479-488, 1991.

31. Fernandez-Rodriguez J, Ayude D, De la Cadena MP, et al: Alpha-L-fucosidase enzyme in the prediction of colorectal cancer patients at high risk of tumor recurrence. Cancer Detect Prev 24: 143-149, 2000.
32. Hutchinson WL, Johnson PJ, Du MQ, et al: Serum and tissue alpha-L-fucosidase activity in the pre-clinical and clinical stages of hepatocellular carcinoma. Clin Sci (Lond) 81: 177-182, 1991.

33. Ichikawa D, Henda K, Withers DA, et al: Histo-blood group A/B versus $H$ status of human carcinoma cells as correlated with haptotactic cell motility: approach with A and B gene transfection. Cancer Res 57: 3092-3096, 1997.

34. Kawano T, Takasaki S, Tao TW, et al: Altered glycosylation of beta 1 integrins associated with reduced adhesiveness to fibronectin and laminin. Int J Cancer 53: 91-96, 1993.

35. Pochec E, Litynska A, Amoresano A, et al: Glycosylation profile of integrin alpha 3 beta 1 changes with melanoma, progression. Biochim Biophys Acta 1643: 113-123, 2003.

36. Bartsch JE, Staren ED and Appert HE: Adhesion and migration of extracellular matrix-stimulated breast cancer. J Surg Res 110: 287-294, 2003.

37. Bogoevska V, Horst A, Klampe B, et al: CEACAM1, an adhesion molecule of human granulocytes, is fucosylated by fucosyltransferase IX and interacts with DC-Sign of dendritic cells via Lewis X residues. Glycobiology 16: 197-209, 2006.

38. Seales EC, Juardo GA, Brunson BA, et al: Hypersialylation of beta1 integrins, observed in colon adenocarcinoma, may contribute to cancer progression by up-regulating cell motility. Cancer Res 65: 4645-4652, 2005.

39. Renkonen J, Paavonen T and RenkonenR: Endothelial and epithelial expression of sialyl Lewis(x) and sialyl Lewis(a) in lesions of breast carcinoma. Int J Cancer 74: 296-300, 1997.

40. Matsuura N, Narita T, Mitsuoka C, et al: Increased level of circulating adhesion molecules in the sera of breast cancer patients with distant metastases. Jpn J Clin Oncol 27: 135-139, 1997.

41. Ding KF and Wu JM: Expression of sialylated carbohydrate antigens and $\mathrm{nm} 23-\mathrm{H} 1$ gene in prognosis of breast cancer. Zhejiang Da Xue Xue Bao Yi Xue Ban 33: 326-339, 2004.

42. Magnani JL: The discovery, biology, and drug development of sialyl Lea and sialyl Lex. Arch Biochem Biophys 426: 122-131, 2004.

43. Dimitroff CJ, Lechpammer M, Long-Woodward D, et al: Rolling of human bone-metastatic prostate tumor cells on human bone marrow endothelium under shear flow is mediated by E-selectin. Cancer Res 64: 5261-5269, 2004.

44. Allahverdian S, Wojcik KR and Dorscheid DR: Airway epithelial wound repair: role of carbohydrate sialyl LewisX. Am J Physiol Lung Cell Mol Physiol 1: L828-L836, 2006.

45. Cai YH, Alvarez A, Alicaide P, et al: Abrogation of functional selectin-ligand expression reduces migration of pathogenic $\mathrm{CD}^{+} \mathrm{T}$ cells into heart. J Immunol 176: 6568-6575, 2006.

46. Brown JR, Fuster MM, Li R, et al: A disaccharide-based inhibitor of glycosylation attenuates metastatic tumor cell dissemination. Clin Cancer Res 12: 2894-2901, 2006.

47. Lu S and Long M: Forced dissociation of selectin-ligand complexes using steered molecular dynamics simulation. Mol Cell Biomech 2: 161-177, 2005.

48. Ramphal JY, Zheng ZL, Perez C, et al: Structure-activity relationship of sialyl Lewis X-containing oligosaccharides. 1. Effect of modifications of the fucose moiety. J Med Chem 37: 3459-3463, 1994

49. Somers WS, Tang J, Shaw GD, et al: Insights into the molecular basis of leukocyte tethering and rolling revealed by structures of P- and E-selectin bound to SLe(X) and PSGL-1. Cell 103: 467-479, 2000.

50. Zipin A, Israeli-Amit M, Meshel T, et al: Tumor-microenvironment interactions: the fucose-generating FX enzyme controls and adhesive properties of colorectal cancer cells. Cancer Res 64: 6571-6578, 2004

51. Hakomori S: Structure, organization, and function of glycosphingolipids in membrane. Curr Opin Hematol 10: 16-24, 2003.

52. Zhang Y, Zhang XY, Liu F, et al: The roles of terminal sugar residues of surface glycans in the metastatic potential of human hepatocarcinoma. J Cancer Res Clin Oncol 28: 617-620, 2002.

53. Xia L, McDaniel JM, Yago T, et al: Surface fucosylation of human cord blood cells augments binding to P-selectin and E-selectin and enhances engraftment in bone marrow. Blood 104: 3091-3096, 2004.

54. Kaila N and Thomas BE 4th: Design and synthesis of sialyl Lewis $(\mathrm{X})$ mimics and $\mathrm{E}$ - and P-selectin inhibitors. Med Res Rev 22: 566-601, 2002.

55. Zeisig R, Stahn R, Wenzel K, et al: Effect of sialyl Lewis Xglycoliposomes on the inhibition of E selectin-mediated tumour cell adhesion in vitro. Biochim Biophys Acta 1660: $31-40,2004$ 